\title{
Research on Brand Heritage Model Construction and Activation Strategy Based on Brand Asset Theory
}

\author{
Li Zhe ${ }^{1}$, Zhu Zhu ${ }^{1 *}$ and Tian Huan ${ }^{2}$ \\ ${ }^{1}$ Chinese Academy of Lifestyle Design, Beijing Institute of Fashion Technology, Beijing, 100028, China \\ ${ }^{2}$ Department of Electronics and Information Engineering, Lanzhou Vocational Technical College, Lanzhou,730070, China
}

\begin{abstract}
In the context of the acceleration of economic globalization and the influence of multiculturalism, people's lifestyle has changed, new demands have been made on brands, and many old names are facing the brand crisis. Therefore, through the study of brand equity theory and the elements of brand heritage, this article constructs a five-factor relationship model of brand heritage, and uses case analysis to sort out the impact of changes in modern lifestyle on China's time-honored brands, and propose the legacy activation strategy of the time-honored brands. The aim is to make the China's time-honored brands take full advantage of the brand heritage and combine the effective measures of modern cultural communication to enhance the core value of the brand and realize the inheritance and development of the brand culture.
\end{abstract}

\section{Introduction}

Social progress has increased the level of consumer demand for products. In addition to the functionality of the product, aesthetics, design, and the lifestyle and lifestyle attitude represented by the brand have gradually become consumers' reference indicators for purchase. In addition, the rapid development of the Internet has led many foreign brands to enter the Chinese market, and these changes have given Chinese people more choices when purchasing goods. China's time-honored brands have problems such as vague brand positioning and backward business concepts. Therefore, in this environment, many established brands have begun to face brand crisis and even decline.

China's time-honored brands should keep pace with the times, cultivate their ability to act on opportunities in a changing market environment, and curb the aging process of brands. Keller (1999) once proposed that attention should be paid to the issue of brand aging. The core of this problem is the loss and shrinkage of brand equity, but brand equity is not an overnight result. The problem of brand aging runs through the long-term management of the brand [1]. Brand heritage, as a unique gene of the time-honored brand, plays an important role in brand equity. Therefore, research on brand heritage activation strategy has important practical significance and social value.[1]

This article starts with the brand equity theory and related models and brand heritage theory, and proposes a brand heritage activation model. At the same time, through analysing the case, it is sorted out how to activate China's time-honored brands heritage under the modern lifestyle.

\section{Status and trends of theoretical research on brand equity and brand heritage}

\subsection{Status of research at domestic and foreign}

\subsubsection{Brand equity theory}

The concept of brand equity was originally proposed by David A. Aaker (1991). This concept answers the question of norms for brand management. At present, academic circles have researched brand equity based on three dimensions: enterprise, market, and consumer. From an enterprise perspective, the Marketing Science Institute (MSI) proposed that brand equity is a collection of joint activities and behaviours of different subjects, such as consumers and channel employees [2].From a financial perspective, Aaker (1991) believes that brand equity is the sum of assets or liabilities associated with the brand [3].For consumers, Keller (1998) believes that brand equity refers to a brand's ownable, credible, relevant, and unique promise provided to consumers [4]. Netemeyer (2004) concluded by studying six different brands: Understanding depth, value, and brand equity are the core of brand equity, which directly affects consumers' willingness to buy; And brand awareness, organization association, and brand familiarity indirectly affect consumers' purchase intentions [5]. Raggio (2007) believes that marketing has a direct effect on the core of brand equity, thereby increasing the value of brand equity. Domestic scholar Lu Taihong (2002) provided research directions for future brand equity evaluation

*Corresponding author's e-mail: 120839127@qq.com 
through analysis and comparison of domestic and foreign brand equity theories. Yu Chunling and Zhao Ping (2003) believed that consumers are the main factor affecting brand equity, and focused on the brand trust structure. Zhou Xiaodong and Zhang Shengqian (2004) compared the existing brand equity evaluation methods and proposed that the future research problem is how to separate brand assets from intangible assets. Xin Jie (2012) believes that a positive corporate image has a positive impact on brand equity.[2][3][4][5]

\subsubsection{Brand heritage theory}

The brand heritage theory was originally proposed by Urde, Greyser, and Balmer (2007). They believed that brand heritage includes brand life, brand core values, brand development history, brand history, brand symbols, and company managers must attach importance to brand heritage. [6] Subsequently, Wiedmann (2011) based on the research of Urde and other scholars (2007), extracted five new elements of brand heritage. In recent years, Balmer and Wei Feng Chen (2015) first applied the theory of brand heritage to the research of China's time-honored brands.[6]

\subsection{Theoretical research trends}

In summary, brand equity theory is a hot topic in academic research, but a lot of current research only stays at the theoretical level. In the future, there will be a trend from theoretical level to empirical level research. Through experience and analysis of examples, Enrich the connotation of brand equity theory and brand equity model. In addition, with the advent of the digital age, the application of high-tech such as big data, artificial intelligence and cloud computing in brand asset management and evaluation will be the main research direction in the future. The reasonable application of the above technologies will explore the periodic brand asset fluctuation Influencing factors have become possible, helping brands open new understanding of consumer perception and brand association.

At present, the research of brand heritage related theories is mainly focused on how to accurately measure, but whether the measurement dimensions are thorough and whether the choice of quantitative indicators is reasonable are worth further consideration in the future. Although the brand heritage theory has been applied by foreign scholars to study the China's time-honored brand "Tongrentang", it is only used to reveal why the Chinese old brand is important to multiple generations of consumers and does not use the old brand in a brand crisis. Research on brand heritage theory. Therefore, this will be a new research topic in academia.

\section{Status and Challenges of China's time-honored Brands in Modern Lifestyle}

In 2017, the Ministry of Commerce determined that there were 1,128 established brands in the country, but according to data from the Ministry of Commerce, only $10 \%$ of the established brands are in good condition, with an average history of more than 160 years. More than $60 \%$ of the industry distribution is mainly in food, medicine, Catering. The regional distribution is mainly concentrated in the eastern region, of which 180 are in Shanghai, accounting for the largest number in the country. Beijing, Zhejiang, and Jiangsu also have more established brands, with an average of about 100 in each region. Therefore, analysing the challenges in the development of the time-honored brand is a prerequisite for solving the brand crisis. According to the report of "China's Time-honored Brand Development Index" for 2018, data analysis was conducted in five dimensions: market power index, innovation power index, awareness index, reputation index, and loyalty index, and was conducted according to the time-honored brand development index region.

\subsection{Regional Overview of Time-honored Brand Development Index}

The regional distribution of the long-established brand development index Top100 is basically the same as the whole. The top three are: Shanghai 20, Beijing 18, and Zhejiang 13, which are ahead of other regions in terms of number.

Specific index comparisons found that the main regions have their own characteristics. Beijing's timehonored brands are leading other major regions in terms of average innovation ability, market power, awareness, and reputation. The average brand development performance is most prominent; Guangdong's timehonored brands have low average innovation power and awareness, but ranks first in loyalty This is because Guangdong Medicine has a long history. (Table 1)

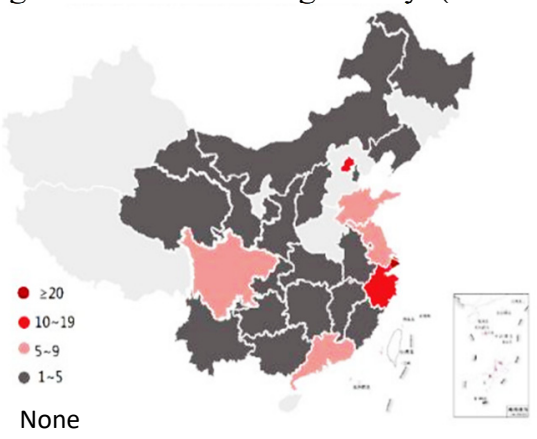


Table 1. Comparison of time-honored brand indexes in major regions

\begin{tabular}{|l|c|c|c|c|c|c|}
\hline Main area & Total index & Market Power & Innovation Power & Cognition & Reputation & Loyalty \\
\hline Shanghai & 34.6 & 34.6 & 34.6 & 34.6 & 34.6 & 34.6 \\
\hline Zhejiang & 34.8 & 17.1 & 27.9 & 50.1 & 68.5 & 29.2 \\
\hline Beijijn & 37.6 & 18.8 & 31.3 & 52.9 & 70.7 & 33.3 \\
\hline Guangdong & 32.6 & 15.7 & 23.7 & 40.3 & 68.5 & 34.7 \\
\hline Average & 34.90 & 21.55 & 29.38 & 44.48 & 60.58 & 32.95 \\
\hline
\end{tabular}

brands actively embrace the Internet. Thirty-four timehonored brands have entered Tmall's time-honored sales top 300 and 13 companies have entered the Top 100 list of brand development indexes. In the brand development index rankings, Wufangzhai ranked first with outstanding innovation and recognition, and Guyuelongshan and Zhiweiguan ranked second and third, respectively. (Table 2 and Figure 1)

There are 91 established Chinese enterprises in Zhejiang, ranking fourth in the country. Unlike most industrial consumer goods brands in Shanghai, Zhejiang's timehonored brands are concentrated in categories with local cultural characteristics such as Chinese medicine, rice wine, silk, tea, and handicrafts. Zhejiang time-honored

Table 2. Main Indexes of Zhejiang's Time-honoured Brands

\begin{tabular}{|c|l|c|c|c|c|c|c|}
\hline Ranking & Time-honored brand & Market Power & Innovation Power & Cognition & Reputation & Loyalty & Total index \\
\hline 1 & Wufangzhai & 31.3 & 73.5 & 78.9 & 63.7 & 67.5 & 61.4 \\
\hline 2 & Guyuelongshan & 40.4 & 30.4 & 61.1 & 71.6 & 52.9 & 47.1 \\
\hline 3 & Zhiweiguan & 20.3 & 43.6 & 72.4 & 70.7 & 29.1 & 44.0 \\
\hline 4 & Nverhong & 37.6 & 29.5 & 57.6 & 72.8 & 27.3 & 41.9 \\
\hline 5 & Zhangxiaoquan & 21.2 & 32.4 & 76.3 & 71.9 & 21.6 & 40.5 \\
\hline 6 & Zhizhonghe & 29.0 & 28.3 & 45.5 & 72.7 & 44.6 & 40.2 \\
\hline 7 & Zhuyangxin & 36.0 & 18.9 & 12.7 & 68.2 & 88.1 & 40.0 \\
\hline 8 & Shouxiangu & 21.9 & 22.0 & 41.3 & 78.2 & 58.8 & 38.8 \\
\hline 9 & Laohenghe & 16.8 & 25.6 & 52.8 & 78.9 & 42.7 & 38.0 \\
\hline 10 & Xilingyinshe & 13.0 & 36.6 & 54.5 & 75.4 & 23.3 & 37.2 \\
\hline
\end{tabular}

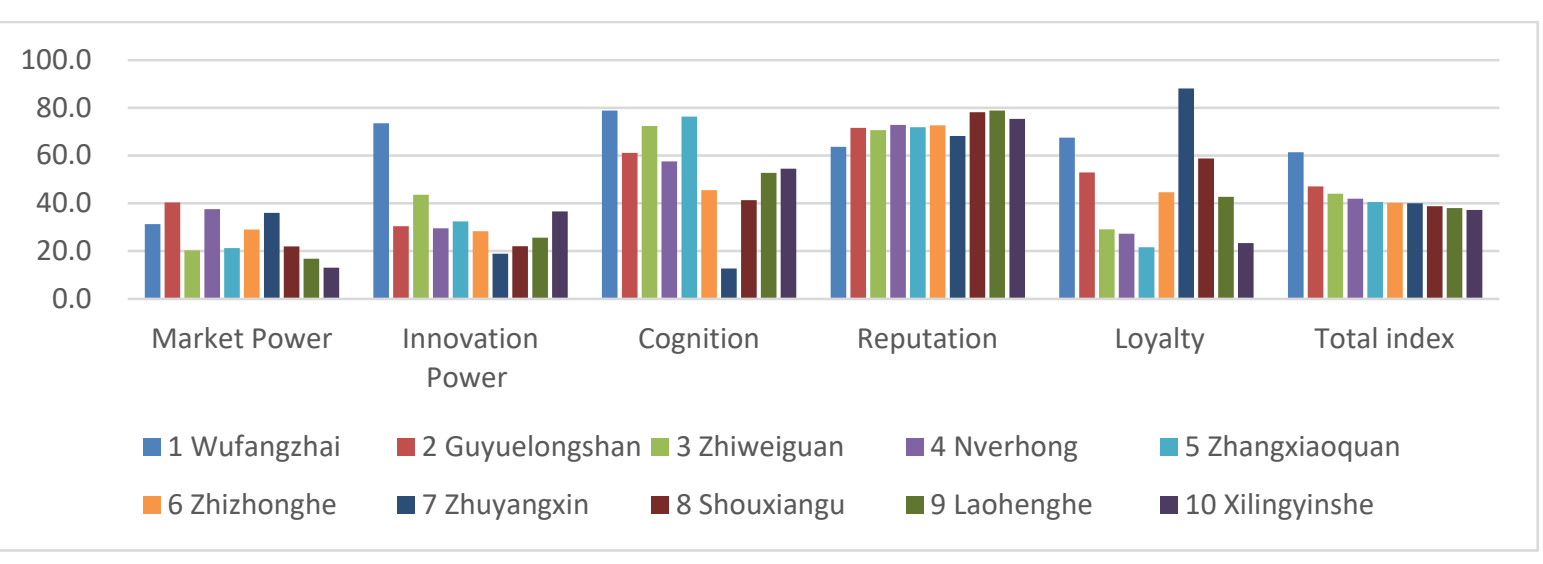

Figure 1 Analysis of Zhejiang's Time-honored Brand Index

\subsection{Analysis of Key Areas of Time-honored Brand Development Index_-Beijing}

There are 117 old Chinese enterprises in Beijing, ranking second in the country. The old brands are widely distributed in food, medicine, wine and tea, as well as daily necessities. Among them, the number of old tea brands is the largest in the country.
In addition to the loyalty index, the other four indicators of Beijing's time-honored brands are first in the country, and 18 companies have entered the TOP100 list of brand development indexes, second only to Shanghai. Among them, Tongrentang and Xinhua Bookstore occupy the top two with great advantages, and brands such as Daoxiangcun are closer. (Table 3 and Figure 2) 
Table 3. Main Indexes of Beijing's Time-honored

\begin{tabular}{|c|l|c|c|c|c|c|c|}
\hline Ranking & Time-honored brand & Market Power & Innovation Power & Cognition & Reputation & Loyalty & Total index \\
\hline 1 & Tongrentang & 48.6 & 83.4 & 85.7 & 65.7 & 59.1 & 68.7 \\
\hline 2 & Xinhuashudian & 48.6 & 64.7 & 88.7 & 66.3 & 35.5 & 60.1 \\
\hline 3 & Daoxiangcun & 27.2 & 52.0 & 70.8 & 72.5 & 17.2 & 46.5 \\
\hline 4 & Yidege & 21.0 & 29.0 & 57.7 & 68.0 & 87.5 & 45.9 \\
\hline 5 & Baihua & 33.5 & 35.7 & 65.5 & 74.1 & 36.1 & 45.5 \\
\hline 6 & Zhangyiyuan & 13.6 & 24.7 & 57.1 & 78.9 & 79.1 & 43.1 \\
\hline 7 & Caibai & 19.0 & 40.5 & 63.7 & 79.1 & 31.2 & 43.0 \\
\hline 8 & Zhongcha & 17.1 & 38.2 & 57.6 & 72.9 & 38.7 & 41.1 \\
\hline 9 & Dongan & 14.0 & 55.2 & 71.8 & 50.7 & 12.0 & 40.2 \\
\hline 10 & Niulanshan & 20.7 & 28.1 & 64.8 & 68.3 & 43.3 & 40.1 \\
\hline
\end{tabular}

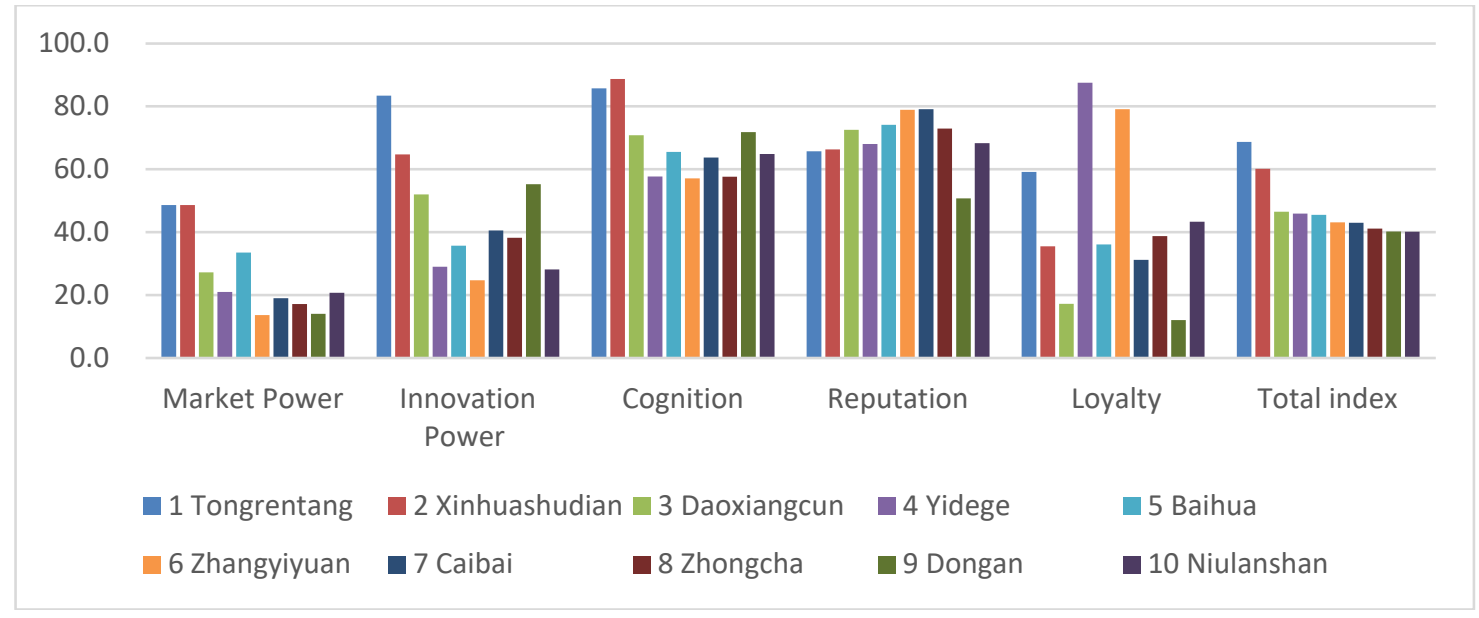

Figure 2 Analysis of Beijing's Time-honored Brand Index

\subsection{Analysis of Key Areas of Time-honored Brand Development Index_—Shanghai}

As the earliest area where ethnic industry and commerce began to sprout, there are 180 established and longestablished enterprises in Shanghai, with a variety of established and long-established consumer goods brands.
No matter from the number of brands or the richness of industry categories, Shanghai is the first in the country.

The top ten established brands in the Shanghai area involve a variety of industries such as clothing, shoes and hats, daily necessities, sports and sports goods, food and catering. (Table 4 and Figure 3)

Table 4. Main Indexes of Shanghai's Time-honored Brand

\begin{tabular}{|c|l|c|c|c|c|c|c|}
\hline Ranking & Time-honored brand & Market Power & Innovation Power & Cognition & Reputation & Loyalty & Total index \\
\hline 1 & Hengyuanxiang & 100.0 & 88.5 & 98.4 & 67.7 & 36.0 & 81.9 \\
\hline 2 & Meijiajing & 40.6 & 97.1 & 87.7 & 56.5 & 35.6 & 66.2 \\
\hline 3 & Huili & 50.6 & 60.0 & 100.0 & 55.5 & 39.7 & 59.9 \\
\hline 4 & Hongshuangxi & 46.0 & 43.4 & 72.2 & 60.8 & 72.1 & 55.3 \\
\hline 5 & Guangming & 15.6 & 64.3 & 77.1 & 74.8 & 55.1 & 54.2 \\
\hline 6 & Mali & 32.0 & 37.1 & 76.1 & 56.0 & 61.7 & 48.2 \\
\hline 7 & Gujin & 14.0 & 55.5 & 80.5 & 65.7 & 31.7 & 46.8 \\
\hline 8 & Meilin & 19.4 & 37.4 & 64.1 & 75.0 & 51.0 & 44.6 \\
\hline 9 & Guanshengyuan & 18.7 & 54.5 & 72.9 & 66.9 & 17.2 & 44.6 \\
\hline 10 & Laomiao & 21.5 & 47.6 & 62.3 & 70.2 & 23.1 & 43.0 \\
\hline
\end{tabular}




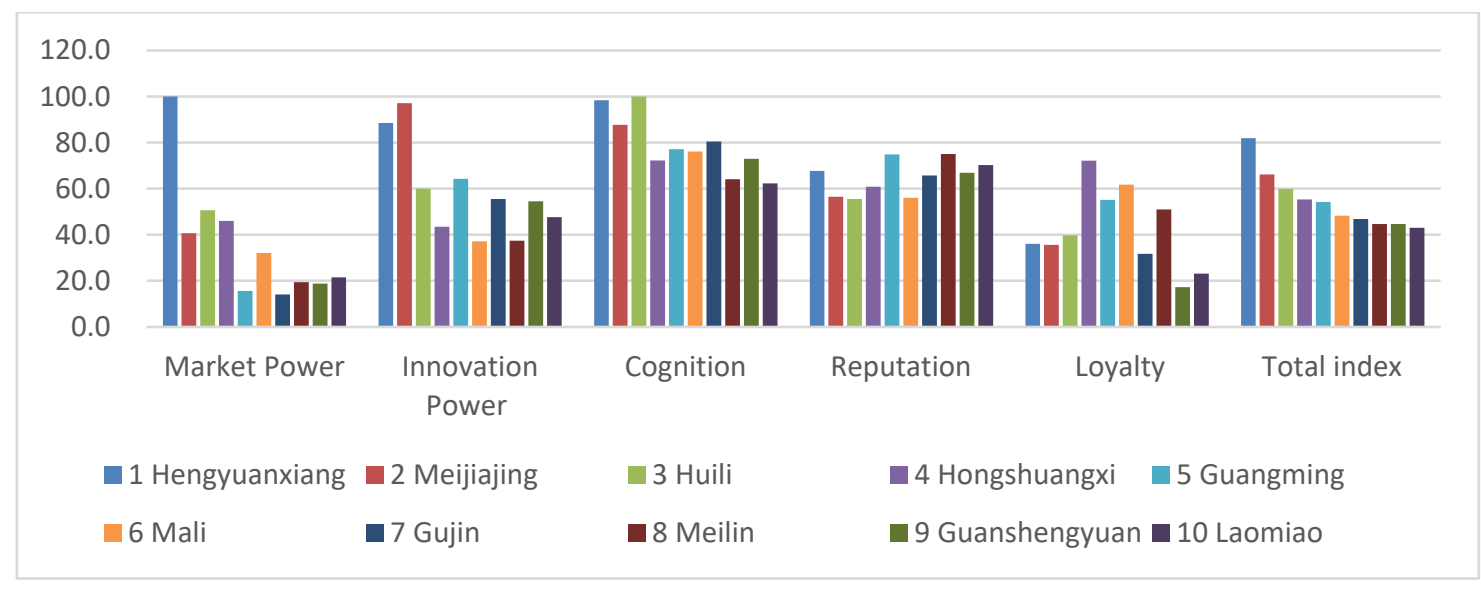

Figure 3 Analysis of Shanghai's Time-honored Brand Index

\subsection{Analysis of Key Areas of Time-honored Brand Development Index_-Jiangsu}

Jiangsu has 96 time-honored enterprises, ranking third in the country, and the industry is evenly distributed.

Table 5. Main Indexes of Jiangsu's Time-honored Brand
Jiangsu's time-honored brands have weak average market power and innovation power, but Jiangsu's time-honored brands have the most balanced development, and the brand development index gap is small. (Table 5 and Figure 4)

\begin{tabular}{|c|c|c|c|c|c|c|c|}
\hline Ranking & Time-honored brand & Market Power & Innovation Power & Cognition & Reputation & Loyalty & Total index \\
\hline 1 & Yanghe & 13.2 & 51.7 & 71.7 & 70.3 & 32.4 & 45.0 \\
\hline 2 & Hengshun & 17.9 & 27.7 & 56.9 & 79.2 & 44.4 & 39.9 \\
\hline 3 & Huatuo & 20.1 & 15.9 & 43.0 & 65.7 & 91.5 & 39.8 \\
\hline 4 & Xiefuchun & 4.8 & 43.0 & 67.4 & 72.6 & 24.2 & 38.7 \\
\hline 5 & Yuyuan & 41.8 & 28.7 & 20.8 & 70.0 & 28.9 & 37.0 \\
\hline 6 & Leiyunshang & 10.3 & 35.0 & 55.2 & 70.8 & 27.0 & 36.0 \\
\hline 7 & Songhelou & 16.1 & 22.1 & 37.4 & 66.2 & 57.2 & 34.8 \\
\hline 8 & Yuej ialaopu & 24.3 & 33.0 & 41.3 & 56.3 & 24.9 & 34.4 \\
\hline 9 & Cunrentang & 2.9 & 39.7 & 50.3 & 56.9 & 26.3 & 32.6 \\
\hline 10 & Gaogou & 32.1 & 20.0 & 37.2 & 62.8 & 23.7 & 32.6 \\
\hline
\end{tabular}

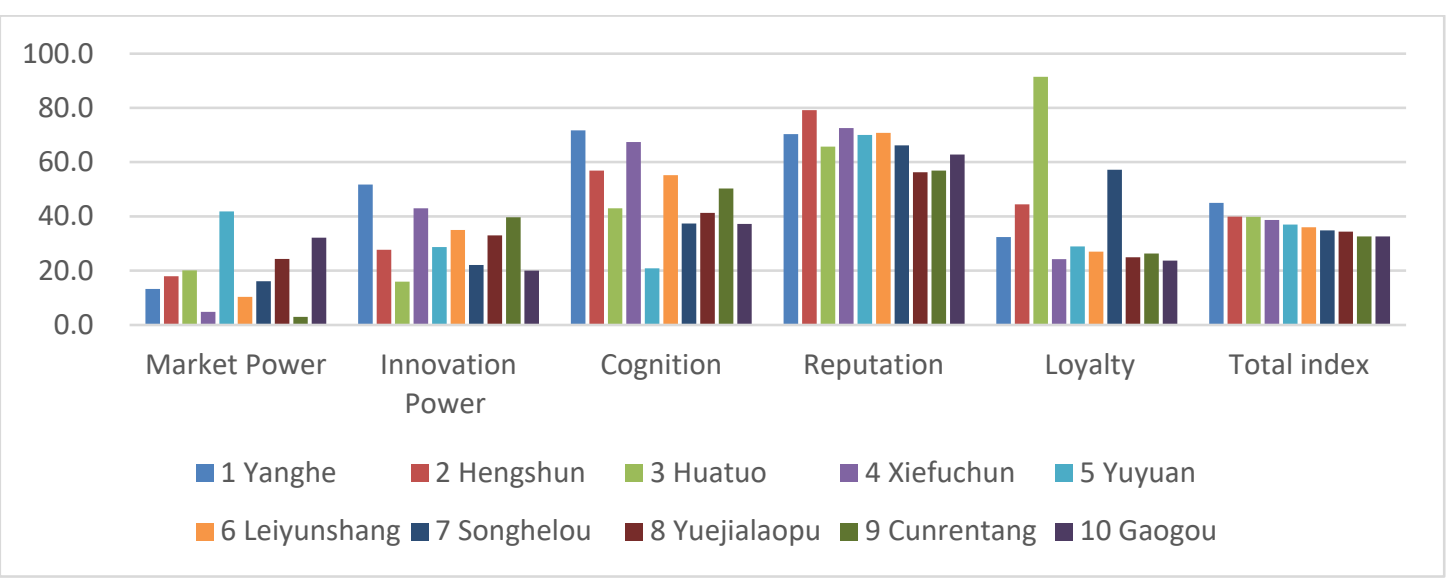

Figure 4 Analysis of Jiangsu's Time-honored Brand Index

\section{New paths for the activation of China's time-honored brands heritage}

\subsection{Building a Brand Heritage Activation Model}

The great advantage of the new retail era is that consumer-centric data drive is the weapon. Without consumers, there is no brand. Therefore, this article focuses on the two theoretical models of brand equity from the perspective of consumers. 


\subsubsection{Pentagram model of brand equity}

The Marketing Science Institute (MSI) 's research on the brand equity model is based on the perspective of corporate profits and market competition, without considering the role of brand equity in enhancing the brand premium. And the "pentagram model" of brand equity refined by David A. Aaker (1991) can better reflect the potential value of brand equity. He believes that brand equity is composed of brand awareness, brand awareness, brand association, brand loyalty, and other brand proprietary assets [7]. (Figure 5) [7]

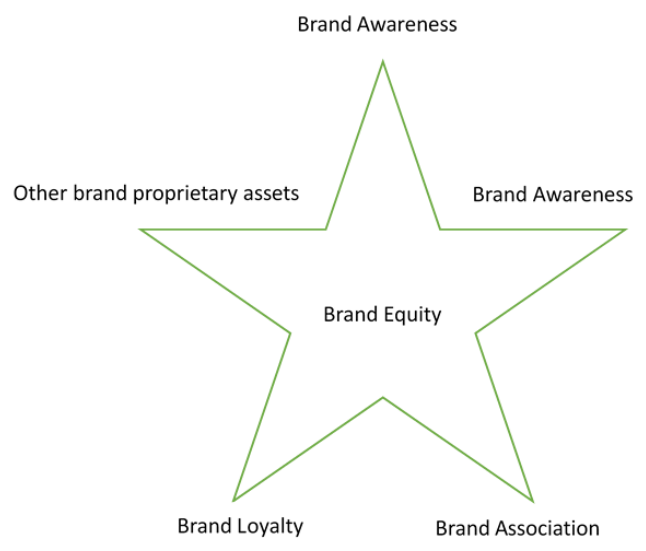

Figure 5 Pentagram model of brand equity

In the five-star model, brand awareness can measure the effectiveness of the brand recognition system, which mainly depends on the memory response of consumers; Brand awareness represents the degree of consumer understanding of a brand's characteristics, history, products, services, etc., and it is used to evaluate the brand value system, that is, the degree of brand differentiation, depending on the consumer's cognitive system; Brand Lenovo represents a series of explicit and implicit information related to the brand generated by consumers through the brand image; It is the sum of consumers' self-thought and attitude towards the brand, which can evaluate the favourable degree of the brand knowledge system in the market. Brand loyalty represents consumers' psychological bias towards a brand, and is mainly used to evaluate the acceptance of the brand meaning system; Brand proprietary assets include brand logos, names, patented technologies, etc. Signs and names belong to the symbol system, and the value lies in enhancing brand awareness; Patented technology belongs to the benefit system, and its value lies in providing credit guarantees for consumers.

\subsubsection{CBBE pyramid model}

The goal of brand management is to establish a longterm stable relationship with consumers. Therefore, Kevin Lane Keller (2001) constructed the customerbased brand equity model (CBBE).Saliency, performance, image, evaluation, feeling, and resonance constitute the six major elements of this model, and the brand is created through the four steps of brand identity, brand connotation, brand response, and brand relationship [8].(figure 6)

The establishment of a brand identity is the beginning of a brand. Whether consumers are familiar with the brand; Whether you are willing to choose to buy first can reflect the distinctiveness of the brand identity. Brands who want to maintain consumer relations in the long run also need to have a unique brand connotation. Brand connotation mainly includes two factors: brand performance and brand image. The former is the concrete performance of brand connotation (brand effectiveness and quality); The latter are abstract expressions (personality and value, brand history, etc.).

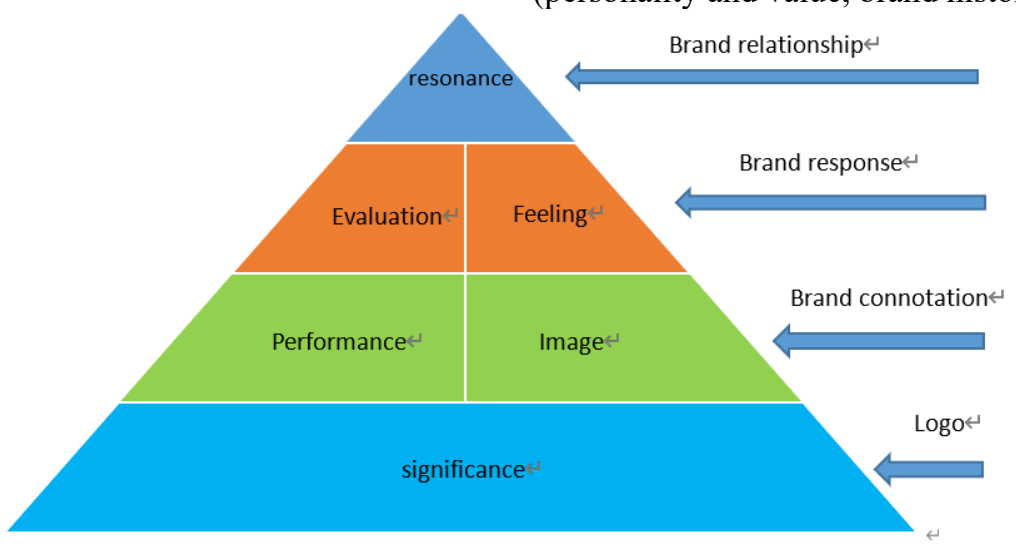

Figure 6 CBBE pyramid model

The CBBE pyramid model is basically like the fivepointed star model, with similarity in popularity, performance, awareness, and associativity in image, but it is different from the five-pointed star in two other levels. Keller (2001) further emphasized that brands need to establish relationships with consumers and guide consumers to generate correct brand responses. The two elements of brand response (evaluation and feeling) are explained from the two dimensions of consumers' rational and emotional perception of the brand Yes, evaluation is a consumer's rational claim on the brand, that is, reliability, quality, superiority, etc.; Feeling is a consumer's perceptual claim to the brand, which is reflected in whether the brand allows consumers to obtain social recognition and satisfaction. 


\subsubsection{The brand heritage activation model}

Holbrook (1994) proposed that consumers will have nostalgia complex at any age, which is a stable psychological trend for consumers. The time-honored brand itself is a concrete manifestation of the past lifestyle, and its unique brand heritage is the natural condition for creating a nostalgic atmosphere for consumers. Time-honored brands should use brand heritage as a medium for establishing brand relationships and emotional connections with consumers, and give play to the huge nostalgia value behind the brand. Blackston (1992) pointed out that the relationship between consumers and corporate brands, there are two elements of outstanding and recognized brand relationships, that is, consumer trust and satisfaction with the brand [10].It can be seen that China's time-honored brands have inherent advantages in establishing brand relationships with consumers. The brand relationship can be understood as a psychological phenomenon caused by a series of psychological activities. Therefore, the reconstruction of the relationship between the timehonored brand and the consumer should also be progressed layer by layer, divided into three stages of development: Attraction recognition stage, application experience stage, resonance and win-win stage.

With the development of mobile technology, the overlap between the Internet and people's lifestyles is constantly increasing, but due to individual differences between consumers, consumer groups have gradually begun to segment based on interests. In the face of many market segments, brands need to find common attributes among consumers, and allow consumers to feel the temperature of the brand on the basis of meeting consumers' basic needs for products and services.

By combing the above two types of brand equity theoretical models and combining current consumer needs, the author believes that the brand equity CBBE model divides the brand response generated by consumers more finely, making companies more targeted in the adjustment of brand asset management decisions. Therefore, this article builds a brand heritage activation model based on the relationship between brand heritage and brand assets, and the CBBE pyramid model.(Such as Figure 7)

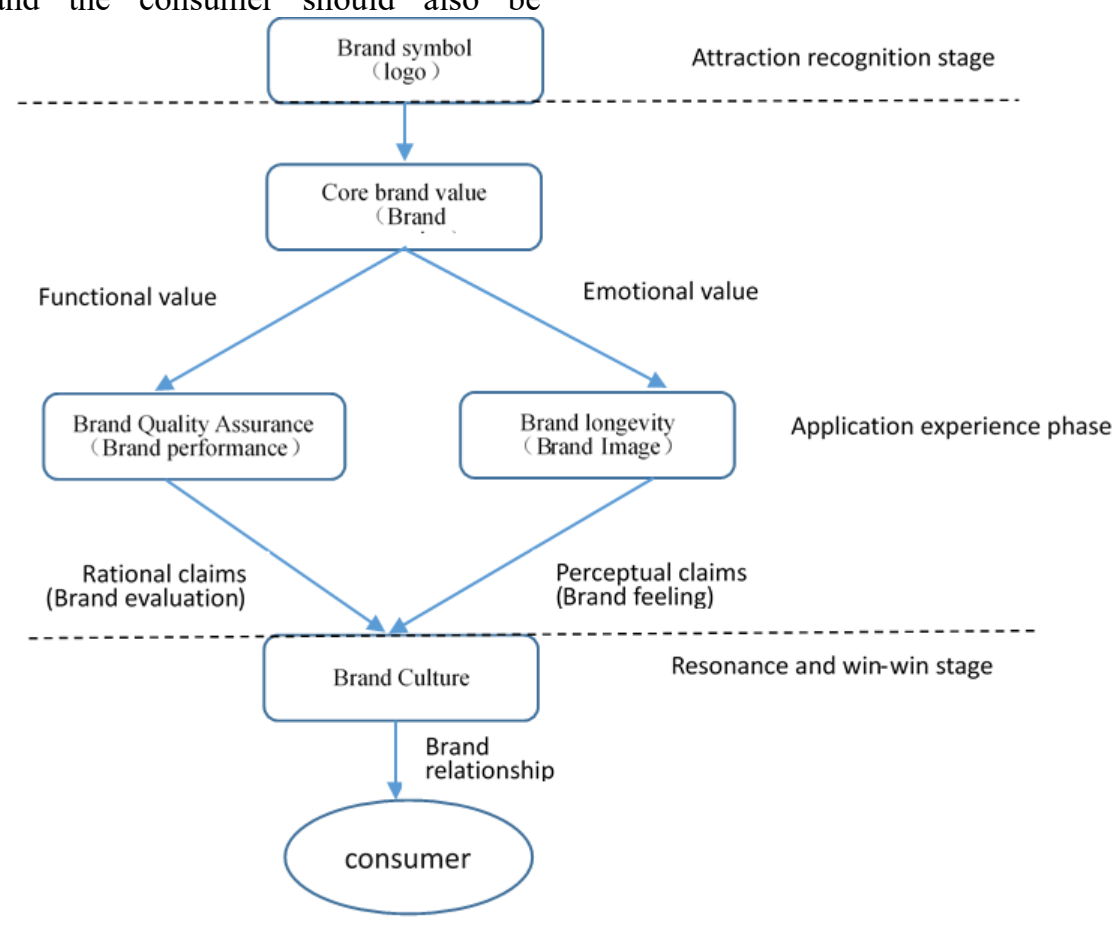

Figure 7 Brand heritage activation model

\subsection{Brand Symbol Activation Strategy}

In the stage of attracting recognition, a unique brand symbol is an important start to the activation of brand heritage. The ultimate brand symbol also has a leading significance for the accurate transmission of the brand's core values. The acceleration of the pace of life has led people to pay attention to time costs. Time-honored brands should be the first to allow consumers to understand the brand in a faster way. The consumers are more willing to understand the core value of appreciating higher value brands. Therefore, the activation of brand heritage should start with the simplification of brand symbols.

- Graphics of brand symbols.

The digital lifestyle makes modern people prefer images to quickly obtain information. Compared with recognizing text, Chinese characters have evolved from hieroglyphs, which is a kind of graphic. The time-honored brand symbols can appropriately learn from the visual processing of fonts in type design, and increase consumers' memory of the brand in the stage of attracting recognition.

- Differentiation of brand symbols. 
With the change of media environment and the public's demands for spiritual consumption, brand development has entered the IP era. The time-honored brand culture has the potential to create IP, and high-quality, unique IP can highlight the core value of the brand in the mind of consumers. Time-honored brands can also form differentiated brand positioning by creating unique brand IP, and then highlight their core brand values in the design of brand symbols based on brand positioning, so that brand symbols have a core meaning to communicate, so that brand core values can be used in the application experience Impact on consumers.

- Systematization of brand symbols.

Many time-honored brand symbols have not formed a unified and standardized visual system, and cannot display the attributes of the brand's core values step by step. Gestalt psychology has also shown that consumers and designers do not appreciate the chaotic brand image [12].With the rapid increase of information update frequency, a systematic brand symbol will greatly increase the efficiency and accuracy of brand information transmission, so that consumers can clearly understand the core value attributes of the brand.[12]

\subsection{Brand Core Value Activation Strategy}

The advent of the experience economy era has brought brand competition into a new pattern. Brands have gradually become a carrier to provide customers with a unique experience, and have begun to have the benefits of creating "function" and "emotion".[13] The brand symbol is the channel for consumers' perceptual awareness, and the core value of the brand can establish a rational understanding mechanism for consumers, but it needs to penetrate the value of consumers through application experience. The core value of the brand is divided into three categories: rational value, perceptual value, and symbolic value [14]. Therefore, the application experience method of the brand core value is also divided into three levels.[13][14]

- The rational value experience is to understand the function and quality of the product. When the time-honored brands are communicating in the brand, if they want consumers to have a positive association with the core value of the brand, they need to improve product quality and production and operation efficiency through scientific and technological means. Become the fulcrum of brand quality assurance, and convey brand core value from the dimension of brand functional value.

- Perceptual value experience is a way to understand the emotional value of a brand. With the increasing diversification of consumers' emotional needs, it is not enough for China's time-honored brands to maintain familiar and nostalgic relationships. Experiential marketing should be used to expand the breadth and depth of brand relationship types and enrich the core content of the brand's emotional value.

- The symbolic value experience is a way to feel the personality of the brand, and the brand image can be personalized through this experience. For generations $\mathrm{Z}$, millennials, and generation $X$, the acceptance of new things and the need for personalized consumption are generally higher. The symbolic value experience of the time-honored brand must be based on the current ideal life style, personal opinions and beliefs of consumers. By improving the inclusiveness and continuity of the core value of the brand, it should give the brand new meaning of longevity. The mystery of brand longevity in the world. In summary, the emotional value experience and the selfexpression value experience are based on the emotional value dimension to realize the transmission of the brand's core value.

\subsection{Brand Longevity and Quality Assurance Improvement Strategy}

The core value of the time-honored brand generally includes the two characteristics of longevity and quality assurance. Quality assurance is a functional expression of the brand's core values, and brand longevity is often closely related to consumers' purchase intentions. Tu Yong and Yan $\mathrm{Li}$ (2010) believe that a longer brand history can show that a brand is more trustworthy [15]. This is why it is easier for longevity brands to build lasting relationships with consumers. Therefore, taking advantage of the long-established longevity of timehonored brand trust is the key to guide consumers to the purchase experience.[15]

The improvement of social productivity makes consumers' purchase behaviors of double meanings. On the surface, people spend money on branded products and services, but their essence is to satisfy consumers' spiritual pursuit. However, when the brand's product line is relatively single, consumers' rational and emotional claims on the core value of the brand are naturally limited, which affects the effective promotion of brand culture. Therefore, the time-honored brands should adjust the product matrix in a timely manner in accordance with current consumer preferences, adopt the brand extension strategy to apply the parent brand to new markets, and create favourable conditions for consumers to generate new brand core value propositions and new understanding of brand culture.

\subsection{Brand Culture Activation Strategy}

Consumers form the brand core value proposition through the functional value and emotional value of the brand. When the brand outputs consistent brand core value for a long time, it will constitute the brand culture. A brand culture that gains social recognition makes 
consumers have a strong sense of attachment and loyalty to the brand, thereby establishing long-term brand relationships. Obviously, this long-term relationship does not depend on products, because old products will always be replaced by higher quality, cheaper and novel products, but people's pursuit of a happy life is always the same, because the key factors that constitute happiness are not material. It's psychological [16]. Meeting the consumer's cultural aspirations will also help them pursue a happy life.[16]

- Re-developing the brand culture by using modern management concepts. In the era of the experience economy, the time-honored brands should pay more attention to the use of new business models, combining the established brands with the current life scenes of young people, and shaping consumers' identity of brand culture from a multi-dimensional sensory experience.

- Refine cultural materials in traditional products, and make traditional products become cultural creative products by giving culture with the characteristics of the times. The consumption trend of cultural and creative products is the effect of the effective docking of traditional and modern culture. Unique creative means and modern expression are the best ways to activate traditional culture. The time-honored brand should grasp the new opportunities arising from the change of the times, and realize the reorganization of the culture connotation of the time-honored brand through new methods.

- Focus on shaping the brand spirit and make the brand culture consistent with the value orientation of the emerging consumer class. The time-honored brand should enable consumers to have a spontaneous pride due to their recognition of the brand culture, and cultivate their own fan culture. The establishment of fan culture will form a magnetic field. While maintaining fan loyalty to the brand, it will also attract more consumers to enter and enhance the appeal of brand culture.

\section{5 research conclusions}

Starting from the systematization, differentiation, and graphitization of brand symbols, we have the courage to get rid of the labels of time-honored brands. The use of brand longevity advantages and technology in brand promotion will allow consumers to re-understand the core value of the brand; Let the quality and craftsmanship of time-honored brand's products be recognized again by consumers in terms of function, emotion and value.

The activation of the time-honored brand heritage needs to be effectively combined with modern business concepts and marketing methods. Although many timehonored brands have noticed this, they often target the target market to young people, but the root cause of brand aging has little to do with the age of the target consumer group, but the brand image, brand value proposition, brand culture and Consumers' new lifestyles are disconnected. Therefore, the time-honored brand should understand the characteristics of the current consumer groups, make the brand heritage advance with the times, and make the unique brand heritage in line with the new lifestyle of the moment.

China's time-honored brands should always pay attention to market changes and make innovations in products, services, technologies, and business models based on existing brand heritage. In the era of rapid changes in consumer trends, innovation is the business normal. Maintaining the traditional style and traditional product style of time-honored brand does not mean rejecting innovation; It means that the time-honored brand should focus on the inside, enhance the brand's spiritual value by injecting modern cultural resources into products and services, and finally realize the activation of the time-honored brand heritage.

\section{Acknowledgments}

Thanks for the following fund for supporting this article: Special Fund for Building High-level Teacher Teams in Beijing Institute of Fashion Technology_-Scholar Program of Beijing Institute of Fashion Technology. (Fund Number: BIFTXZ202003)

\section{References}

1. Keller, KL. Managing brands for the long run: Brand reinforcement and revitalization strategies[J]. California Management Review,1999, 41(Spr.):102124.

2. Shen Pengyi. Review of Foreign Brand Equity Theories [J]. Advertising Outlook (Theoretical Edition), 2011 (03): 39-44.

3. Aaker, D.A. Managing Brand Equity; Capitalizing on the Value of a Brad Name[M].New York: Free Press, 1991.

4. Keller. K.L. Brand Synthesis: Multidimensionality of Brand Knowledge[J]. Journal of Consumer Research,2003,29(4):595-600.

5. Netemeyer R.G, Krishnan B. etal, Developing and validating measures of facets of customer-based brand equity [J].Journal of Business Research 2004.57:209-224.

6. Urde, Greyser S.A., Balmer J.M. Corporate brands with a heritage[J]. Journal otbrand management,2007,159(1):4-5.

7. Cui Mingxin. The Establishment and Application of Brand Asset Evaluation Model [D]. Daqing Petroleum Institute, 2006.

8. Keller, K.L.Building. Customer-Based Brand Equity. [J]Marketing Management,2001 (7-8),14-19.

9. Holbrook MB, Schindler RM. Age, Sex, and Attitude Toward the Past as Predictors of Consumers, Aesthetic Tastes for Cultural Products [J]. Journal of Marketing Research, 1994, 26(8):412-422. Keller, K. 
L. Building. Customer-Based Brand Equity. [J]Marketing Management,2001 (7-8),14-19.

10. Blackston. Max. The Qualitative Dimension of Brand Equity[J]. Journal of Advertising Research,1995,4,35.

11. He Yan, Deng Honghong. Research on Cross-Media Narrative Strategy of the Palace Museum IP [J]. World of Sound Screens, 2019 (07): 73-75.

12. Li Dongmei, Wang Jiamin. Culture Features and Design Performance of Time-honored Signboards [J]. Explore Art, 2008 (01): 103-104 + 144.

13. Chen Dingfan, Zhang Jijun. Brand Experience [J]. Management Science Abstracts, 2004 (06): 33-34 + 62.

14. Yan Li, Tu Yong. Demystifying the SINCE Effect of Brands [J] . Sales and Market, 2010 (22): 3235.

15. Chen Taichun. Discussion on Building Strong Brands of Chinese Enterprises [D]. Southwestern University of Finance and Economics, 2005.

16. Dong Lichao. Research on nostalgic aesthetics and nostalgic consumption [D].Jilin University, 2012. 